\title{
Exiliados interiores
}

Aquiles Montoya

s usted un exiliado interior? Si ocurre que no le agradan los

2 valores propios de este sistema, que no está de acuerdo con las injusticias que engendra, que le resulta desagradable la pobreza de amplias mayorías de la población y que le parece una actitud poco racional el pretender que el sistema capitalista se la mejor opción para la humanidad, ya que, además de depredador social, lo es el medio ambiente, seguramente que lo es. Pero si aún no lo es, es casi seguro que está en camino de convertirse en un exiliado interior, porque el sistema no le dejará otra opción.

Por mi parte, viendo como miro las cosas, me parece una actitud interesada la de aquellos que descalifican por "ideologizados" a quienes, como yo, compartimos una visión marxista del sistema capitalista. Esto es una actitud crítica, reflexiva, analítica y cuestionadora del mismo, pero sobre todo humanista. ¿Por qué habría de hablarse de ideología en este caso y no en el de aquellos que están a favor del sistema? Esto parece una actitud irracional, además de excluyente. Quienes estamos en contra del sistema pareciera que no tenemos derecho de vivir al interior del país, porque si se nos niega el derecho a pensar y a expresar nuestros pensamientos, es casi como si no existiéramos. En consecuencia, de manera "truculenta", nos convierten en exiliados interiores.

Por otro lado, siendo que los partidos políticos otrora revolucionarios, o simplemente de izquierda, aceptan jugar con las reglas del sistema y en la medida que ello les ha llevado a renunciar, en su práctica política, a sus principios revolucionarios, tampoco me parece que se pueda militar en ningún partido de los existentes, con lo cual estamos siendo condenados al ostracismo político partidista, esto es, al exilio interior.

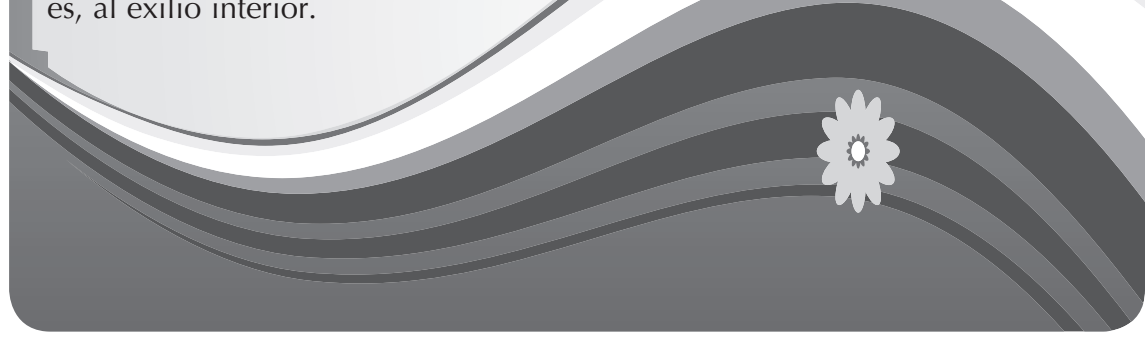


Dicho entre paréntesis, ¿qué sentido tendrá participar en política si al hacerlo se hace con el fin de alcanzar un puesto de elección popular desde el cual contribuir a la mejora social, pero ocurre que para ser electo, se exige: no pensar por cuenta propia, no poseer instrucción notoria, ser deshonesto, acomodarse a las circunstancias, responder a los intereses de quienes detentan el poder, cualquiera que sea su naturaleza, y ser disciplinado, obviamente? ¿Por qué cree usted que algunas personas no están de diputados? Evidentemente, porque caen mal, como mal caen todas aquellas personas que dicen lo que piensan y piensan lo que dicen, además de tener un perfil muy diferente al que exige la democracia representativa. Si aún tiene alguna duda, revise la calidad de los presidentes de los Estados Unidos, o para no ir tan lejos en el espacio y el tiempo, la de los presidentes salvadoreños, desde Martínez en adelante.

Pero es que, además, la mayoría de las universidades -sin darse cuenta- se van acomodando a las reglas del sistema, lo cual nos deja sin siquiera aquellos oasis de libertad y de utopía que en el pasado tuvimos. En las universidades, de hoy, existe poco espacio para la utopía, para la reflexión y la producción teórica, éstas se ocupan más de la opinión pública, de la delincuencia, de los parques, de la educación básica, de los edificios, de cosas prácticas, y aunque muy útiles, como que no muy les corresponden o, en todo caso, les corresponden menos que el auténtico quehacer académico propio de las universidades. Situación que convierte nuestro exilio interior en algo desagradable y vacío, lo cual, si bien es propio de los exilios por los lejanos que se tornan la gente y sus problemas, resulta más duro cuando estando tan cerca, estamos tan alejados de la realidad con la que quisiéramos vérnoslas. Hablamos de la realidad verdadera y no de la realidad figurada y que es recogida, a menudo, de mala manera, en las encuestas de opinión.

Se podrá decir que la democracia exige de esas adecuaciones. Y que la consecución de la democracia como valor supremo, justifica las metamorfosis ocurridas en nuestra sociedad y en sus gentes. Al punto de que ahora nos parece que con ser antineoliberales es suficiente, y quizá hasta demasiado, como si acaso el neoliberalismo (doctrina económica del capitalismo) y la globalización (una frase más del capitalismo) fueran los auténticos males y no el capitalismo que los engendra. Cuando miramos así las cosas, $-y$ nos parece que con justificada razón- no obstante, casi nadie quiere aceptar tales visiones lúcidas de la realidad, por considerarlas fuera de época, anacrónicas, dicen. Es obvio, entonces, nuestra condición de exiliados interiores. 
Ciertamente, la democracia histórica o real, i.e., desde aquella que se vive en los Estados Unidos hasta la que practican en Haití, para no referirme a una nación africana, pasando por aquella de las Ilamadas Repúblicas Bananeras, no creo que sea algo como para sentirse muy orgulloso. Con motivo de las recientes elecciones en los EEUU algunos de los brillantes analistas políticos con que contamos los salvadoreños, nos manifiestan que la clase política salvadoreña -la de Merino, Arévalo, la Ileana, la Milena y Alvarenga- deberían aprender de la forma en que se practica la democracia en ese país del norte, desafortunadamente, para tan ilustres doctores y licenciados admiradores de la democracia estadounidense, otros analistas internacionales han comparado la democracia "made in USA" con la democracia "bananera", la cual conocida es, por su poca transparencia y limpieza, así como por su irrespeto de la institucionalidad. De modo que tampoco soy un amante o seguidor de tal forma política. ¿Siendo como somos, cómo podríamos convivir aquí y ahora con nuestros connacionales, con nuestros hermanos cercanos y lejanos -cuando nos visitan por Navidad- en este maravilloso país de la sonrisa? Como usted comprenderá, no nos queda otra alternativa que ser exiliados interiores. Pero no pongan esa cara compungida. ¡ $\mathrm{Va}$ mos! Que si usted siente ser uno de los nuestros, déjeme decirle que no es para tanto, resulta mucho peor ser un vergonzante, un hipócrita o un vendido. Y vea, ¡cómo abundan! Con todo, ejemplo de dignidad política y de principios, por ahí lo ofreció Fidel en la tele, tal vez algo aprendan los políticos pragmáticos, si es que entendieron.

Por si a usted le parecen insuficientes los argumentos anteriores, permítame agregar que también odiamos el consumismo que nos quieren imponer los medios publicitarios, caracterizados por la trivialidad de sus páginas de opinión, -excepción hecha de uno o dos columnistas y de algún canal de TV, en algunas contadas ocasiones-. Nos referimos a los articulistas: desde los duros-blanditos hasta los arcoiris, sin olvidar los mensajes a la conciencia de pastores, presidentes, alcaldes, "los que saben latín" y otra caterva más de plumíferos, pagos y no pagos, que nos empujan a leer las páginas de opinión de periódicos extranjeros, profundizando, con ello nuestro exilio interior. Afortunadamente, algunos tenemos acceso a la red internacional.

Igualmente nos resistimos a caer en la terrible práctica de los tarjeta-habientes, que terminan devorados o embargados por los onerosos intereses de los nuevos usureros, lo cual nos ubica necesariamente en el exilio interior y nos obliga a vivir en austeridad, lo cual, obviamente, no podría ser de otra manera siendo como somos exiliados, aunque exiliados interiores. $Y$ 
no nos queda de otra que saborear "el duro pan del exilio", aunque algunos en la pasada década lo tuvieron blando, dulce y dorado. Quizá, por eso, a su retorno pronto se integraron al sistema y ahora poseen ONG, fundaciones, chances en el gobierno como asesores o funcionario públicos, o bien en los paraísos terrenales: los organismos internacionales.

Pero no culpe a nuestro paísito, ya que El Salvador no es la excepción, sino que es parte de la regla mundial. Los males que aquí sufrimos, igual o peor, se sufren en Argentina, Chile, México, Europa, Asia, etc. El mundo, dirá Galeano, "está patas arriba"; sin embargo, yo creo que somos nosotros, los exiliados interiores los que vemos las cosas al revés. La historia del mundo, de la humanidad, la real, la vivida, obviamente, ha sido la que ha estado al derecho; los que han vivido al revés, han sido los otros: Sócrates y Espartaco, Galileo y Dalton, Marx y Engels, el Che, Ellacuría y Romero, $y$ todos aquellos que buscaron de una u otra manera, cambiar la sociedad y en ello se les fue la vida. Por eso, precisamente, es que ahora somos exiliados interiores. El sistema te absorbe o te exilia, cuando no te mata.

Pues si, como le iba diciendo, lo de ser un exiliado interior no es nada nuevo, lo descubrieron los españoles que se quedaron en España, luego del arribo del Generalísimo al poder y lo canta Sabina, en la canción a propósito del entierro de quien fue sepulturero mayor y a cuyo sepelio no asistió el Ku Klux Klan pero mandó su adhesión. Y ahora España va bien, luego que de tanto añorar a Franco, encumbraron al poder a sus sucesores del PP; para los gitanos, marroquíes y los pobres, la cosa no ha cambiado, por eso es que los okupas siguen ocupando pisos y los etarras matando gente, aunque la Cumbre Iberoamericana, con Flores a la cabeza, los condone por terroristas, como si asesinar a 35,000 personas cada día por hambre no fuese una forma más cruel de terrorismo, y no sólo por la cantidad, sino porque no hay razón material para que ello ocurra. Aparte de que el hambre de los pobres es la riqueza de los ricos. ¿No le parece que exiliarse internamente es casi una necesidad biológica?

¿Cuál será el mundo al revés? ¿El de los exiliados interiores, el de los ciudadanos votantes, o el de aquellos que les vale sombrilla todo este bolado y que igualmente no votan, aunque por razones diferentes? Cuantitativamente, éstos últimos son la mayoría, luego siguen los votantes irredentos y finalmente, nosotros, los que sin ser anarquistas -no sé si por convicción o por incomprensión- somos antisistema y cargamos en nuestras mentes, o en nuestras cabecitas humeantes, -como dicen- la gran solución: la alternativa popular. $\mathrm{Y}$ el pueblo está tan, pero tan jodido, que ya 
no tiene siquiera tiempo para hacer algo diferente a la búsqueda diaria por los frijoles, las papas, la casha, el mate, la coca, la hierbal, las piedras, el alcohol o la pega. Desde Alaska al Cabo de Hornos, desde Kamchatka hasta el estrecho de Gibraltar, en Asia, en África, en Oceanía o en Australia la cosa está igual de jodida. En todas partes alguien mira Internet y en todas partes muchos más ni siquiera saben qué cosa es tal bolado. Globalizados los ricos que del globo los pobres ni siquiera tienen donde caer muertos y mientras tanto en Madrid y Barcelona, se pelean por Figo y un chileno maldice a los socialistas de nuevo en el poder, aunque ahora domesticados, por haber quedado otra vez excluidos del mundial. En El Salvador ya no se sabe a quien culpar, por la desgracia de nuestro fútbol, quizá si probaran culpar a ARENA, ciertamente, igual no se conseguiría ir a un mundial, pero al menos los ortodoxos se los agradecerían. Y aunque no es mucho, pero es nada.

La cochinada nos ha alcanzado a todos, inclusive a nosotros, los exiliados interiores, luego que el más nacionalista de los partidos políticos en el poder renunciara a tener moneda propia; ciertamente aquello de Duarte cuando reconoció la real sumisión del país a los $\mathrm{EU}$, al besar de hinojos la bandera de las barras y las estrellas, no es nada; o resulta una nimiedad que el Mayor aceptara sin protestar la derrota electoral ante la truculencia de la CIA; o bien, parece poca cosa el que Cristiani firmara los acuerdos de paz, contra su maldita voluntad, cuando los gringos se lo ordenaron; o aquella declaración de Calderón Sol, respecto a Puerto Rico. Siempre hemos sabido, lo dependientes que son los paísitos de pipiripau como el nuestro, pero querer sacarle ventaja a la dependencia, ya resulta el colmo del cinismo. Poco faltó para que el anuncio de la dolarización, lo hiciera Flores el 15 de septiembre. O bien, argumentar que para evitar los sufrimientos de nuestros compatriotas que emigran a los EE. UU. y nos envían dólares, decidiéramos convertirnos formalmente en un Estado Libre Asociado.

Pero tampoco es para armar el gran relajo, el gran problema no es que circulen billetes verdes, que en vez de don Cristóbal veamos a personajes gringos, no es ninguna diferencia relevante, y que hayamos perdido la facultad de hacer política monetaria, - ¿y cuándo la hemos hecho?- no es para morirse. El gran problema es que somos un país capitalista subdesarrollado y dependiente. Y ahora, lo que está ocurriendo es que poco importa guardar las apariencias. Aunque siendo como somos, -bayuncos es la palabra más suave que se me ocurre- seguiremos haciendo desfiles militares el 15 de septiembre del otro año, y el otro y el otro. Como si los militares hubieran tenido algo que ver con la independencia polí- 
tica de España y como si tal hecho hubiera marcado el inicio de algo relevante, trascendente, importante para los pueblos centroamericanos.

Déjeme darle una razón más por lo cual es necesario optar por el exilio interior. Esta tiene que ver con aquel viejo principio que nos enseñaba que las batallas que no se va a ganar es mejor no darlas. Nuestros trabajadores, parece que nunca lo han escuchado, porque realizan heroicas jornadas de lucha, a veces huelgas interminables, para que al final todo se reduzca a que reinstalen a los trabajadores despedidos con motivo de la huelga. Cosa semejante, les ocurre a los diputados efemelenistas y les seguirá ocurriendo, mientras no definan con precisión sus objetivos de corto, mediano y largo plazo y actúen conforme a los mismos y no reaccionando a las coyunturas que genera el gobierno.

Si con toda esta información que le proporciono de manera gratuita, aproveche que gratis ya casi no es nada en el mundo, no se siente también un exiliado interior, no tendré más remedio que decirle que usted es un masoquista por vocación.

Pero bien, el ser un exiliado interior, no significa que no nos importe la realidad. Si resultamos exiliados es precisamente porque nos importa mucho.
Nuestro exilio es una consecuencia de nuestra forma de ver, entender y querer que sea la realidad. No se trata de un auto-exilio, motivado por el miedo. Aquí hemos estado y seguiremos, mientras tengamos energías para seguir. El ser un exiliado interior no significa: pasividad, ni resignación, ni esperar que las cosas cambien. El exiliado auténtico reflexiona y llama a la reflexión, se informa e informa, complota contra la realidad que rechaza y busca, entre sus semejantes a otros que también quieran conspirar. Ciertamente, el complot y la conspiración, siempre serán consideradas delictivos, porque con ellas se busca transformar la realidad de quienes dominan y controlan la sociedad, de modo que no les tema a las palabrejas.

¿Y qué espacios tenemos los radicales auténticos para escapar de nuestro exilio interior? En la actualidad, existen algunos movimientos que a fuerza de ser consecuentes, están llegando a descubrir que muy poco se puede conseguir sin hacer estallar los estrechos marcos del sistema capitalista. Estos son los movimientos sociales: como los ecologistas, los campesinos con tierra o sin ella, sean indígenas o no, los movimientos de las obreras de la maquila, los habitantes del tugurio, los obreros tradicionales, las feministas, etc. Lo cuales, obviamente, no tienen porque ser excluyentes en su radicalidad. 
Las mujeres podrán decir con justa razón a los hombres: "luego de que sus luchas han sido cooptadas por el sistema, acompáñenos en nuestra lucha como nosotros los acompañamos en las de ustedes". Pero con una gran diferencia y ésta es: que ahora, la liberación de las mujeres arrastra la liberación de los hombres. Vea usted, las mujeres pelearon por su incorporación al mercado laboral. ¿Y qué consiguieron? Pues que el sistema las incorporara para media jornada, con menores prestaciones y en condiciones precarias de trabajo. Pero no sólo eso, sino que a costa de excluir a muchos hombres. Las consecuencias familiares de tal fenómeno, así como el de la flexibilización laboral, están aún en marcha pero lo que se puede observar ya, no resulta para nada agradable: desempleo masculino, rupturas familiares, alcoholismo y drogradicción, miseria, frustración, suicidios, etc.

Los ecologistas podrán plantear: si seguimos arrasando el planeta con tal de hacer dinero, nos quedaremos sin planeta y de nada servirá el dinero. Como el capitalismo no acepta otra racionalidad diferente a la de hacer dinero, quienes estamos por la vida no tenemos otra opción que salvar a los capitalistas y a quienes de ellos dependen, de su propia destrucción y para ello es preciso acabar con el capitalismo.

Las luchas campesinas seguirán cobrando fuerza, y el movimiento de las obreras maquileras, una vez que sean disciplinadas por la fábrica y organizadas a fuerza de ser sobreexplotadas serán incontenibles, así como las de los obreros tradicionales despertados por la flexibilización laboral y los pobres y marginales arrastrados por las nuevas luchas, serán todos a una, la gran fuerza liberadoras de los nuevos tiempos.

Es claro que también caben los intelectuales y estudiantes consecuentes, los maestros y los empleados públicos que van quedando, si se ponen las pilas y entienden los signos de los nuevos tiempos.

Los que si parecen ir quedando excluidos son los políticos profesionales, los que han hecho de la política su modus vivendi o robandi.

Vea usted que sencillo resulta escaparse del exilio interior: luchar por la igualdad de los igualdad de los hombres y mujeres en un mundo con futuro. Ciertamente es lo opuesto a lo que tenemos, pero la humanidad sólo se plantea aquellos problemas a los que puede encontrarles solución. Algo así sostenía nuevo viejo maestro de economía política.

¿Le sorprende? Usted pensó que la invitación al exilio interior era algo así como una invitación al existencialismo, al escapismo, al valeverguismo. No se equivocó. Pero deseábamos Ilevarlo al límite, 
a tocar fondo, para que desde allí, se incorpora con fuerza y con esperanzas en la naturaleza humana. Como le decíamos, si somos exiliados no es porque queramos refugiarnos en algo así como un más allá de la realidad. No, porque nos choca esta realidad social, es que no aceptemos convivir en paz con ella. De modo que ahora la onda está en los movimientos sociales y no en los partidos políticos electo- reros, lo cual no significa que no se haga política.

La cosa está en ir construyendo desde la base misma formas alternativas de economía, de política,de cultura, de sociedad. El proceso es más largo, más sinuoso, pero si está claro el horizonte, cualquier esfuerzo puede ser bien orientado y por pequeño que sea, brindará frutos sanos y carnosos. 